\title{
The Effectiveness of Teaching Academic Procrastination Reducing Strategies on Academic Self-regulation in the Secondary School Students in Tabriz
}

\author{
Ayatollah Fathi' ${ }^{1}$ Eskandar Fathi Azar ${ }^{2}$, \\ Mir Mahmoud Mirnasab ${ }^{2}$ and Rahim Badri Gargari ${ }^{2}$ \\ ${ }^{1}$ Department of Educational Psychology, Tabriz University \\ ${ }^{2}$ Department of Education, University of Tabriz.
}

DOI: http://dx.doi.org/10.13005/bbra/1939

(Received: 23 July 2015; accepted: 12 October 2015)

\begin{abstract}
This study aimed to evaluate the effectiveness of teaching procrastination reducing strategies on academic self-regulation in secondary students in Tabriz. For this purpose, 36 students with high academic procrastination were selected through a pilot study and screening, and were divided into two experimental and control groups. The experimental group received a training package on procrastination reducing strategies and the controls went through normal training. Pre-test and post-test were done using the Pintrich \& De Groot's self regulatory learning strategies questionnaire (1990). The results showed that the means of the two experimental and control groups were significantly different in the metacognitive component of self-regulated learning strategies $(F=6.94, p \leq 0.05, \eta=0.178))$. However, there was no significant difference in the component of cognitive self regulated learning strategies between the control and experimental groups $(F=1.94, p \leq 0.05)$. The results can help school counselors and school psychologists to reduce academic procrastination in students.
\end{abstract}

Keywords: Self regulated learning, academic procrastination, strategies to reduce procrastination.

Ellis \& Knaus(1979) considered procrastination as the lack of self-regulatory function and the behavioral tendency to delay what is necessary to be done to achieve the goal. Research indicates that there are two kinds of procrastination: behavioral procrastination which means a delay in the completion of major tasks, and decisional procrastination, as a deliberate delay in making a decision within a specified time (Milgram and others, 2000).

Self-regulation, as one of the important life skills in the present world, is the ability to plan and implement activities to achieve the goals

\footnotetext{
* To whom all correspondence should be addressed.
}

(Vavrova, V, Gavora,2015). In a survey of the literature, it is seen that academic procrastination is related with self-regulation which was tested as the dependent variable in this research (Faber and Vohs, 2004; Metcalfe and Mischel, 1999; Uzun-Özer, 2010). According to Pintrich and De Groot (1990), cognitive strategies such as controlling and managing the attempts given in order to cope with academic duties, repeating what is used for learning and understanding, interpreting and organizing are self-regulation. According to the related literature, it is seen that students who use these strategies make less academic procrastination (Faber and Vohs, 2004).Fat'hi, Badri and Beyrami(2013) showed that procrastination was predicted by incremental intelligence beliefs and controlled selfregulation. 
Senecal, Koestner and Vallerand (1995) argued that in the field of education, procrastination was associated with self-regulation practices. They suggested that postponing school assignments was related to a non-self-determined extrinsic motivation. They argued that, according to Deci and Ryan's self-determination theory, their inabilities to start and to continue doing homework were related to the lack of motivation and externally regulated behaviors (cited in Badri and Hosseini, 2010). Ellis \& Knaus(1979) defined procrastination as the lack of self-regulatory function and behavioral tendency to delay what is necessary to be done to achieve the goal. Several potential factors are involved in procrastination (lack of interest in homework, fear of failure, personality, etc.), all of which are defined as self-defeating and failure in self regulation.

\section{Learning strategy usage and procrastination}

Another component of self-regulated learning is the utilization of learning strategies (Alexander, Graham, \& Harris, 1998). Learning strategies are commonly operationalized with measures that capture the use of cognitive strategies (i.e., rehearsal) and metacognitive strategies (i.e., monitoring). Researchers examining procrastination within a self-regulated learning framework have found both cognitive and metacognitive strategy usage negatively associated with procrastination (Howell \& Watson, 2007; Wolters, 2004).

As no research had been done in this field, the present study was carried out to determine the effectiveness of academic procrastination reducing packages on academic self-regulation.

\section{The research hypothesis:}

$\mathrm{H}$ :Teaching the strategies for reducing academic procrastination can enhance students' academic self-regulation.

\section{METHODS}

In this research pretest-posttest with control group was used consisting of one independent variable of teaching academic procrastination reducing strategies and academic self- regulation as the dependent variable. In this study,first a pilot study was conducted in relation to academic procrastination in order to select the students with academic procrastination who were then randomly placed in the experimental and the control groups. The research was conducted in three phases. In the first phase a pre-test on the dependent variable was given to both the control and the experimental groups, in the second phase the training package was performed for the students in the experimental group, then in the third phase the post test on dependent variable was given to both groups.

\section{Training materials}

In this study the package on procrastination reducing strategies, was taught to the experimental group in 10 sessions of 1 hour by an experienced psychology teacher while the control group followed their routine education. It should be noted that the training package was based on the existing studies, the related theories in psychology, and the relevant and appropriate learning principles for the secondary school students. The content validity of the training package was confirmed by professors and teachers and counselors active in this field.

\section{Syllabus}

1) First session: Introduction, motivation and course description

2) Second session: Motivational interviewing

3) Third session: Discussing experiences of procrastination and their negative consequences

4) Fourth session: The beliefs and ideas associated with procrastination

5) Fifth session: Perfectionism, self criticism and fear as underlying procrastination

6) Sixth session: Thoughts associated with procrastination, overcoming inner child

7) Seventh session: Getting organized and getting involved in school activities

8) Eighth Session: Goal setting

9) Ninth Session: Planning

10) Tenth Session: Daily behavior self assessment

\section{Population and sampling}

The study population consisted of all the secondary school students in Tabriz who, according to the statistics, amounted to 3965 persons in 2014. Because of the experimental nature of the study and for theoretical and practical considerations, 36 students with high educational procrastination were selected to form two groups (a boys' class as the control and another one as 
the experimental group) through multi-stage sampling (cluster-randomized).

\section{Tools}

\section{Self-Regulated Learning Strategies Questionnaire (MSLQ)}

This scale was made by Pintrich and De Groot (1990) to measure students' self-regulated learning. The questionnaire consisted of 47 items in two parts of motivational beliefs and selfregulated learning strategies (cognitive and metacognitive ones).For the purpose of this study, only the second part of the questionnaire- the self regulated learning strategies- was used. It included 22 items which measured three aspects of educational self-regulation i.e. cognitive strategies, metacognitive strategies and resource management. 13 items were allocated to cognitive strategies as follows:

Repetition and reviewing items 29, 37.44; expansion which included note taking item 34 , summarizing items 31.45 ; organizing items 26,27 , 39, 42, 47, and comprehension items 32,33.

Metacognitive and resource management strategies included 9 items as follows:

Planning items 38,46; supervision and control items 28, 35, 41, 43; organizing which contained effort and persistence, items 30,36 , and regulatory activity item 40 .

Validity and reliability of self-regulated learning strategies Questionnaire

On the validity of their questionnaire Pintrich and De Groot (1990) found three factors of self-efficacy, internal evaluation, and test anxiety for motivational beliefs and for the scale of self regulated learning strategies they found two factors of using cognitive strategies, and using metacognitive strategies and resource management. They set the reliability of the subscales of self-efficacy, internal evaluation, and test anxiety and the use of cognitive and metacognitive strategies as $0.89,0.87,0.75,0.83$, 0.74 , respectively by Cronbach's alpha. In this study, too, Cronbach's alpha was used to evaluate the reliability of the questionnaire which was found to be 0.75 for cognitive strategies and 0.78 for metacognitive strategies.

\section{RESULTS}

To evaluate the hypothesis asserting that teaching the strategies for reducing academic procrastination can enhance academic selfregulation in students and because of the fact that academic self-regulation is made of two components of cognitive and metacognitive strategies, the MANCOVA was used .For this purpose, the results of the descriptive analysis of the variables after excluding the impact of the pretest variables were provided as in the following table:

The results indicated the fact that in both components the experimental group scored higher than the control group which is also shown in the diagram below.

This section examines the assumptions in multivariate covariance analysis. First we discuss the assumption of homogeneity of regression slope as one of the basic assumptions for covariance analysis.

The test results indicated that the assumption of homogeneity of regression slopes for the analysis of covariance was established and there was a linear correlation between dependent variables and covariates. The Ljung-Box test was used to study the equality of variance-covariance matrices of the dependent variables with the results shown in the following table:

Table 1. The descriptive data of the components of academic self regulation of the control and experimental groups after excluding the effect of pre-test

\begin{tabular}{lllll}
\hline \multirow{2}{*}{ Variable } & Groups & \multicolumn{3}{c}{ Index } \\
\cline { 3 - 5 } & & $\mathrm{N}$ & Mean & SD \\
\hline \multirow{2}{*}{ Metacognitive Strategies } & Experiment & 18 & 27.50 & 1.38 \\
& Control & 18 & 26.38 & 1.03 \\
\multirow{2}{*}{ Cognitive Strategies } & Experiment & 18 & 41.00 & 4 \\
& Control & 18 & 38.88 & 4.12 \\
\hline
\end{tabular}


Table 2. Test of the homogeneity of regression slopes

\begin{tabular}{lcccccc}
\hline Independent variable*covariate & dependent variable & SS & df & MS & F & significance \\
\hline $\begin{array}{l}\text { Group } * \text { pre-test for metacognitive } \\
\text { strategies * pre-test for } \\
\text { cognitive strategies }\end{array}$ & $\begin{array}{c}\text { Metacognitive } \\
\text { Strategies } \\
\text { cognitive Strategies }\end{array}$ & 7.76 & 2 & 3.88 & 2.76 & 0.079 \\
\hline
\end{tabular}

Test results showed that the variancecovariance matrix for the default equality and homogeneity of variance was established.

To examine the assumption of the homogeneity of variances in groups as another pre assumption for the analysis of covariance Levene's test was used .The results are provided in the table below.

Results showed that the assumption of homogeneity of variances across groups was met to carry out the analysis of covariance.

Among the four statistcs of Pillai's, Wilks' Lambda, Hotelling's,and Roy's largest root , the researchers chose Wilks' Lambda for their calculations.

According to the following table it can be said that the Wilks Lambda statistic $(\mathrm{P}<0.05$, F $=3.55$ ) rejected the null hypothesis asserting that the means of the population are the same.

The results of the test of the effects of intergroup contact of post test, by excluding the effect of pre-test showed that there was a significant difference between the means of two experimental and control groups in the component of academic self regulated metacognitive strategies $(F=6.94, p \leq 0.05, \eta=0.178)$. Regarding the criteria for exponential stability of Cohen 1988 ,both components had moderate effects. But in the

Table 3. Box test on the equality of variance-covariance matrices

\begin{tabular}{lcccc}
\hline significance & df2 & df1 & F & Box’s M \\
\hline 0.165 & 208.15 & 3 & 1.7 & 5.44 \\
\hline
\end{tabular}

Table 4. Levene's test for the assumption of homogeneity of variances

\begin{tabular}{llllc}
\hline Dependent variable & F & df1 & df2 & Significance level \\
\hline Metacognitive Strategies & 3.3 & 1 & 34 & 0.078 \\
cognitive Strategies & 0.033 & 1 & 34 & 0.856 \\
\hline
\end{tabular}

Table 5: Multivariate analysis of the components of educational procrastination with regard to the control and experimental groups as independent varaibles according to Wilks Lambda statistic

\begin{tabular}{lcccccc}
\hline Multivariate test & statistic & F & df & Df error & Sig. & $\eta$ \\
\hline Wilks Lambda & 0.814 & 3.55 & 2 & 31 & 0.041 & 0.186 \\
\hline
\end{tabular}

Table 6: Intergroup eeffects of the components of academic procrastination with regard to the control and experimental groups as independent variables

\begin{tabular}{lcccccc}
\hline Variables & SS & df & MS & F & Significance level & Eta-squared \\
\hline Metacognitive Strategies & 10.84 & 1 & 10.84 & 6.94 & 0.013 & 0.178 \\
cognitive Strategies & 32.14 & 1 & 32.14 & 1.94 & 0.172 & 0.057 \\
\hline
\end{tabular}




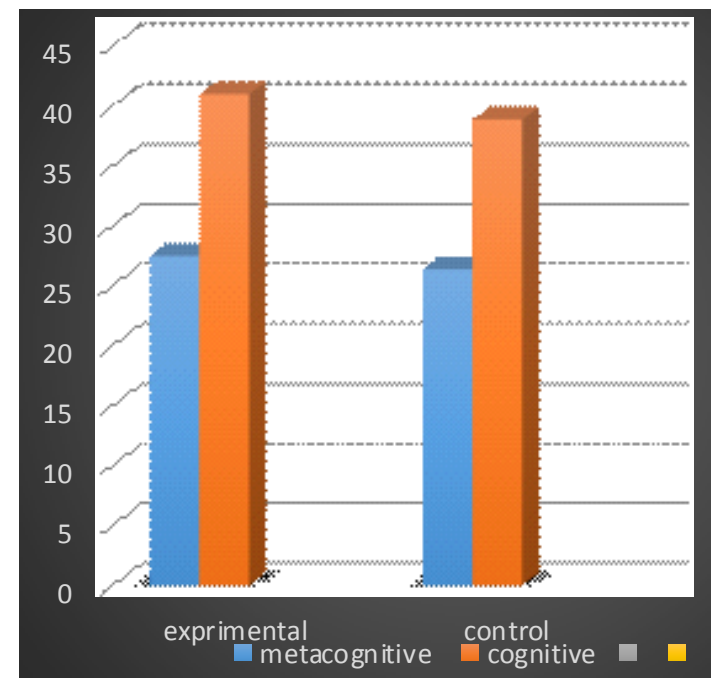

Fig. 1. Diagram of the components of the educational self-regulation in experimental and control groups

component of academic self regulated cognitive strategies $(\mathrm{F}=1.94, \mathrm{p} \leq 0.05)$ there was no significant difference between the control and experimental groups.

\section{CONCLUSION}

Studies have shown that procrastination has such harmful effects as poor educational performance, and low motivation (Semb, Glick and Spencer, 1979). Among its other consequences one can refer to the emotional consequences. Procrastination is a troubling phenomenon and most people know it as harmful and silly. However, it is common in society. Most procrastinating people (about 95\%) wish to reduce their procrastination (O’Brien, 2002). Academic selfregulation in students is one of the most influential variables that influences procrastination (Eun Hee, 2009; Howell \& Buro, 2009; Howell \& Watson, 2007; Wolters,, 2004).

In this regard, this study aimed to evaluate the effectiveness of teaching anti procrastination strategies on academic self-regulation. The results of multivariate analysis of covariance showed that there was a significant difference between the means of two experimental and control groups in the components of metacognitive strategies of educational self-regulation; however, in the components of cognitive strategies there was no significant difference between the two. No research on this issue was found; yet, several studies have been already carried out on teaching strategies to reduce academic procrastination.

In this regard, Ozer, Demir and Ferrari (2013) in a study entitled " Reducing Academic Procrastination Through a Group Treatment Program " after five weeks of teaching the strategies for reducing academic procrastination which was mostly focused on cognitive distortions of procrastination , concluded that the program could significantly reduce academic procrastination both in the post-test and in the follow-up studies. Binder (2000) in a study entitled " The Effects of an Academic Procrastination Treatment on Student Procrastination and Subjective Well-Being “ devoted seven weeks on teaching the strategies for reducing academic procrastination . At the end it was concluded that under this training, procrastination reduced and students' spiritual well-being and life satisfaction improved. Narimani,et al. (2015) in their study concluded that teaching self-regulated learning strategies and problem-solving processes helped students to manage their goal setting, self-control, self-assessment and self-motivation ; and as their goal setting process developed, their motivation for learning strengthened which facilitated learning. Based on the results, it can be said that teaching procrastination reducing strategies can result in academic self-regulation that, in its turn, can help treat academic procrastination.

\section{REFERENCES}

1. Badri Gargari R. Hosseini, F., A Study on the Relationship between learning strategies and Motivational Beliefs with Procrastination in the Students of Tabriz University. News and Reaserches in Counseling Quarterly, 2010; 36: 111-126

2. Narimani, M. Mohammad Amini, Z, Zahed A., Abolghasemi A., A Comparison of the Effectiveness of Teaching Self regulated Learning strategies and Problem Solving on Neglectful Students' Educational Motivation. Journal of School Psychology. 2015; 4 (1). 139-155.

3. Ellis, A., \&Knaus, W.J., Overcoming Procrastination or How to Think and Act Rationally in Spite of life, Inevitable Hassles. 
New York: Institute for Rational Living, 1979.

4. Narimani, M, Mohammad Amini, Z, Zahed, A \& Abolghasemi, A., A Comparison of Effectiveness of Training Self-regulated Learning Strategies and Problem-solving on Academic Motivation in Male Students with Academic Procrastination. Journal of school psychology. 2015; 4(1): 139-155.

5. Fathi, A, badri, R, beyrami, M., The Relationship Between Implicit Beliefs of Intelligence with Procrastination by Mediating Self-regulationof Learning. Journal of educational psychology study. 2013; 10(17).127-145.

6. Faber, R. J., \&Vohs, K. D., To Buy or Not to Buy? Self Control and Self-regulation Failure in Purshase Behavior. In R. F. Baumesister\& K. D. Vohs (Eds.), Handbook of self-regulation: Research, theory and applications. NY: The Guilford Press, 2004.

7. Metcalfe, J., \&Mischel, W., A Hot/Cool-System Analysis of Delay of Gratification: Dynamics of Willpower. Psychological Review, 1999; 106(1), 3-19.

8. UzunÖzer, B., A Path Analytic Model of Procrastination: Testing Cognitive, Affective, and Behavioral Model. Unpublished doctorate thesis, Middle East Technical University, Social Science Institute, Ankara, 2010.

9. Pintrich, P. R., \& De Groot, E. V., Motivational and Self-regulated Learning Components of Classroom Academic Performance. Journal of Educational Psychology, 1990; 82: 33-40

10. Milgram, N. A., \&Tenne, R., Personality Correlates of Decisional and Task Avoidance Procrastination. European Journal of Personality, 2000; 14: 141-156

11. Ellis, A., \&Knaus, W.J., Overcoming Procrastination or How to Think and Act
Rationally in spite of Life, Inevitable Hassles. New York: Institute for Rational Living, 1979.

12. Alexander, P. A., Graham, S., \& Harris, K. R., A Perspective on Strategy Research:Progress and Prospects. Educational Psychology Review, 1998; 10(2): 129-154.

13. Wolters, C. A., Advancing Achievement Goal Theory: Using Goal Structures and Goal Orientations to Predict Students' Motivation, Cognition, and Achievement, Journal of Educational Psychology, 2004; 96: 236-250, doi:10.1037/0022-0663.96.2.236.

14. Howell, A. J., \& Watson, D. C., Procrastination: Association with achievement goal orientation and learning strategies. Personality and Individual Differences, 2007; 43: 167-178, doi:10.1016/j.paid.2006.11.017.

15. Binder, K., The Effects of an Academic Procrastination Treatment on Student Procrastination and Subjective Well-Being. A thesis submitted to the FacuIty of Graduate Studies and Research. Carleton University, 2000.

16. Ozer, B, Demir, A, Ferrari, J., Reducing Academic Procrastination Through a Group Treatment Program: A Pilot Study. Journal of Rational-Emotive \& Cognitive-Behavior Therapy. 2013; 31:127-135.

18. Pintrich, P. R., \& De Groot, E., Motivationaland Self-regulated Learning Component of Classroom Academic Performance. Journal of Educational Psychology, 1990; 82: 33-40.

19. Vavrova, V, Gavora., Comparison of Selfregulation in Children and Adolescents in Children's Home and Protective Educational Facility. Social and Behavioral Sciences 2015; 174: 2524 - 2531. 